Mincey, E. K., Thorson, S. C., and Brown, J. L. (1971). Clinical Biochemistry, 4, 216.

Mincey, E. K., Thorson, S. C., Brown, J. L., Morrison, R. T., and McIntosh, H. W. (1972). Fournal of Nuclear Medicine. In press.

Mitchell, M. L., Harden, A. B., and O'Rourke, M. E. (1960). Fournal of Clinical Endocrinology and Metabolism, 20, 1474.
Murphy, B. E. P., Pattee, C. J., and Gold, A. (1966). Fournal of Clinical Endocrinology and Metabolism, 26, 247.

Oppenheimer, J. H. (1968). New England fournal of Medicine, 278, 1153.

Robbins, J., and Rall, J. E. (1960). Physiological Reviews, 40, 415.

Thorson, S. C., Tsujikawa, R., Brown, J. L., Morrison, R. T., and McIntosh, H. W. (1970). Acta Endocrinologica (Kobenhavn), 64, 630.

\title{
Distinction between Infection and Rejection in Lung Transplantation
}

\author{
P. A. CULLUM, M. BEWICK, KEITH SHILKIN, D. E. H. TEE, P. AYLIFFE, \\ D. C. S. HUTCHISON, J. W. LAWS, S. A. MASON, LYNNE REID, P. HUGH-JONES, \\ A. M. MACARTHUR.
}

\section{Summary}

In distinguishing between infection and rejection after human lung transplantation clinical and radiological features were unhelpful, and even confusing. However, incipient rejection could be predicted and distinguished from infection by monitoring alterations in lymphocyte activity by the rosette inhibition test. Earlier prediction seems possible by detecting circulating lung-binding antibody. The ability to detect changes in the immunological status of a patient, even before clinical deterioration, has fundamental implications for the management of patients after transplantation.

\section{Introduction}

Human lung transplantation has yet to achieve a status comparable with that of certain other organs. All except one of the 27 lung allografts reported in man have failed within one month of surgery, usually resulting in the death of the patient (Organ Transplant Registry, 1971). Among the major obstacles to success are the particular problems of transplantation, especially the risk of infection and the absence of a simple test or tests to predict rejection. The importance of distinguishing between the two is increased in lung transplantation as the clinical features of each are similar, yet their treatment is in so many ways opposed (Wildevuur and Benfield, 1970). Destruction of lung parenchyma during rejection will promote infection in an organ particularly exposed and vulnerable to it, yet increased immunosuppression to treat rejection will inhibit the natural mechanisms of defence against bacterial, fungal, or viral invaders. A minimal but nevertheless effective immunosuppressive regimen should be the object of therapy.

We detail here the relevant clinical, radiological, and immunological findings which we found helpful in preventing and dis-

King's College Hospital Medical School, London S.E.5

P. A. CULLUM, F.R.c.s., Senior Lecturer and Consultant Thoracic

Surgeon
KEITH SHILKIN, M.B., B.S., F.R.C.P.A., Lecturer in Morbid Anatomy

KEITH SHILKIN, M.B., B.S., F.R.C.P.A., Lecturer in Morbid Anatomy
D. E. H. TEE, M.R.C.PATH., Senior Lecturer in Experimental Pathology D. E. H. TEE, M.R.C.PATH., Senior Lecturer in Experimental Pathology P. AYLIFFE, F.I.M.L.T., Chief Technician, Department of Microbiology D. C. S. HUTCHISON, M.R.C.P., Lecturer in Medicine, Chest Unit J. W. LAWS, F.R.C.P., F.F.R., Director, Department of Diagn

P. HUGH-JONES, M.D., F.R.C.P., Consultant Physician and Director Chest Unit

A. M. MACARTHUR, F.R.c.s., Consultant Thoracic Surgeon

Guy's Hospital, London S.E.1

M. BEWICK, F.R.C.S., Senior Lecturer and Consultant Surgeon

Institute of Diseases of the Chest, Brompton Hospital, London S.W.3 LYNNE REID, M.D., F.R.C.P., Professor of Experimental Pathology

\section{Methods}

Diagnosis of Incipient Rejection.-The clinical features, oxygen requirements, and daily chest $x$-ray films were compared with changes in the patient's immunological status. The rosette inhibition test was used to assess alterations in peripheral blood lymphocyte activity as an indication of adequate immunosuppression (Munro et al., 1971). In addition, an increase in the number of rosettes per thousand lymphocytes was noted. The presence of circulating lung-binding antibody was measured retrospectively by immunofluorescent techniques. Frozen sections of normal lung were incubated in the patient's serum and treated with fluorescein-labelled antihuman gammaglobulin.

Prevention of Infection.-A sterile unit for postoperative care (Barlow Leslie \& Partners, Croydon CR9 1PB) was used, which had air counts comparing favourably with those suggested for operating theatres (Williams et al., 1966), and which allowed daily electrocardiographic and radiological examinations without entry across the sterile barrier. All supplementary gas was administered through a $0 \cdot 3$-micron filter (Foramoflow) without humidification through an MC face-mask. Later the same facemask, delivering at least 20 litres of air per minute, was used by the patient as a protection against aerial contamination during transit within the hospital to other departments or outdoors. Monitoring of the patient for bacterial, fungal, and viral pathogens was performed on most days, and bacterial organisms were continually studied for changes in their antibiotic sensitivity. In addition, staff carriers of multiresistant staphylococci were excluded from the sterile area.

Anatomical Pathology.-Shortly after death tissue was taken by needle puncture from the donor lung for electron microscopy. Further material for electron microscopical study was sampled at the routine necropsy, which was performed 20 hours after death. Both donor and residual lungs were removed en bloc and inflated with formalin for subsequent examination.

Details of clinical progress have already been presented (Hugh-Jones et al., 1971). The relevant features are compared with the immunological changes that occurred (Fig. 1).

\section{Infection and Rejection}

PATIENT SEPSIS

Pulmonary sepsis was clinically evident between the ninth and fourteenth postoperative days. At first the patient was ill, his 
minimal respiratory rate and oxygen requirements were raised, and his sputum changed from its previous scanty mucoid character to become excessive and purulent. The chest films showed incomplete expansion of the basal segments of the right lower lobe from the sixth to the thirtieth day, and a small pleural effusion developed on the eighth day. Antibiotics, which had been withheld since the second day, were given. The patient's well-being improved and his minimal respiratory rate and oxygen requirements diminished. After this, clinical chest infection was not apparent in terms of adventitial sounds, purulent sputum, or excessive phlegm production.

Sputum cultures were either sterile or grew commensals until the eleventh day. After this Pseudomonas aeruginosa was present in the sputum in large numbers until death. Occasional growths of Klebsiella aerogenes and Escherichia coli were also

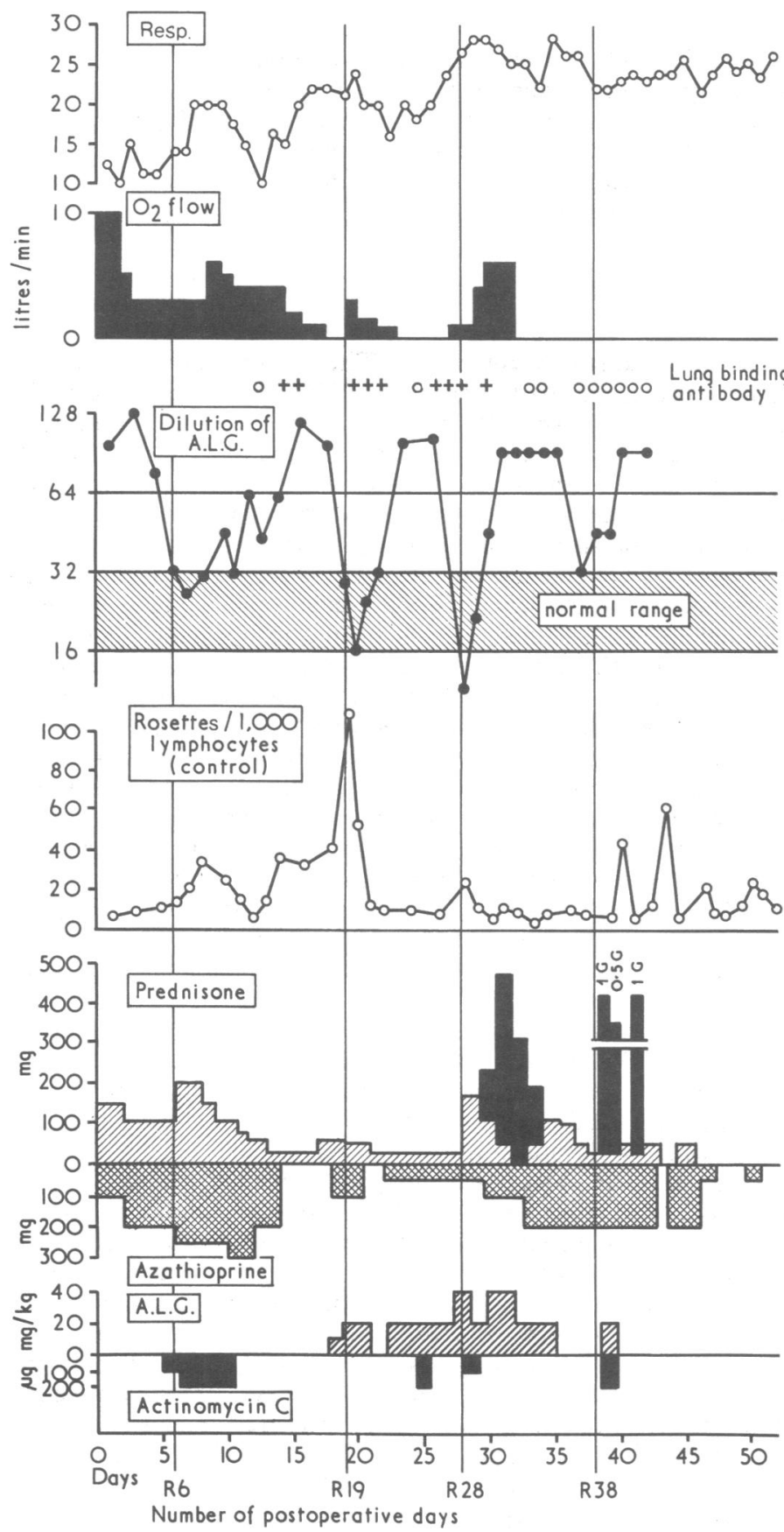

FIG. 1-Four episodes of incipient rejection are indicated by the vertical lines. The respiratory rate is defined as the lowest recorded by the nursing staff during four-hourly observations during any 24-hour period, and the oxygen flow indicates the patient's own requirements. Changes in immunological status indicated by the rosette inhibition test or the presence of circulating lung-binding antibody are explained in the text. found. Other cultures remained sterile or grew commensals. At no time were fungal or virus inoculations positive.

Intermittent pyrexia occurred again after the twenty-seventh day. The sputum remained mucoid although occasional haemoptysis was noted. The right lower zone changes seen radiologically continued to improve. Numerous blood cultures were examined between the thirty-fifth and fifty-third postoperative days, but there was no evidence of blood stream infection except possibly the finding of coagulase-negative staphylococci and Streptococcus faecalis on the thirty-fourth and thirty-sixth days respectively. Tomography taken on the fifty-third day showed disruption at the site of bronchial anastomosis, although at the time the lung was still well expanded.

\section{ROSETTE INHIBITION TEST}

Laboratory evidence of inadequate lymphocyte suppression was present on four occasions; changes in clinical features were present at or within 24 hours of those occasions.

The first drop in the rosette inhibition titre was associated with an increase in the number of rosettes per thousand lymphocytes on the sixth and seventh days. The patient did not feel ill until his minimal respiratory rate increased 48 hours later (on the eighth day) when a small pleural effusion was seen radiologically. There was no evidence of hilar oedema, either at this or at any other time. On the next (ninth) day sputum production became excessive and purulent. An increase in conventional immunosuppressive therapy and daily administration of actinomycin C $200 \mu \mathrm{g}$, accompanied by antibiotics 72 hours later, seemed to reflect the improvement in the patient's well-being, reduction in his respiratory rate and oxygen requirements, rise in the rosette inhibition titre, and decrease in the number of rosettes per thousand lymphocytes (Fig. 1). At the same time his sputum production returned to its previous scanty mucoid character.

The rosette inhibition test showed inadequate immunosuppression for the second time on the nineteenth day, by a fall in titre and an increase in the number of rosettes per thousand lymphocytes, being associated with a decline in the patient's well-being, and by an increase in the minimal respiratory rate and oxygen requirements. Chest films between the sixteenth and twenty-sixth days showed incomplete lower lobe expansion and a small overlying pleural effusion which required aspiration on five occasions. It was not clear either clinically or radiologically whether infection or rejection was causing the patient's illness. Slight increases in previous immunosuppressive therapy, together with daily intravenous antilymphocytic globulin (A.L.G.) $20 \mathrm{mg} / \mathrm{kg}$ was followed by clinical and immunological improvement as before. Antibiotic therapy remained unchanged during this time.

Two further similar episodes of inadequate lymphocyte suppression were associated with significant patient deterioration. Both episodes seemed to respond within a few hours to highdosage intravenous prednisone. Each time there was concurrent improvement in the rosette inhibition test. The first episode was also characterized by a delayed rise in minimal respiratory rate and oxygen requirements. On neither occasion did the sputum change from its previous mucoid character.

\section{IMMUNOFLUORESCENT STUDIES}

The presence of circulating lung-binding antibody was looked for during the last three rejection episodes. It was detected four and two days before change in the rosette inhibition test on the first two of these occasions, with previous serum samples being negative. Disappearance of circulating antibody was also demonstrated after each of these episodes. No antibody was found during the last incipient rejection episode. 


\section{Pathological Findings}

Necropsy.-The trachea and both major bronchi were filled with blood clot. The residual left lung was firm and nodular without pleural adhesions. Its cut surface was typical of advanced fibrosing alveolitis with architectural destruction, scarring, and cysts; in addition, there was much aspirated blood. On the right side the pleura of the donor lung was smooth except where it was adherent at the site of thoracotomy incision. Ulceration, mainly of the cartilaginous part, began abruptly at the line of the anastomosis and extended down to the recipient bronchus for about $2 \mathrm{~cm}$. This ulcer had penetrated the walls of both the bronchus and the immediately adjacent branch of the pulmonary artery to the right upper lobe. The fatal haemorrhage had occurred through the $2-\mathrm{mm}$ opening so formed. The cut surface of this lung was normal apart from considerable aspiration of blood.

Microscopical Examination.-At the site of the anastomotic breakdown there was much necrosis and mixed inflammation. Numerous and various organisms were identified in the Gramstained sections. Within the donor lung there were a variety of changes. Many alveoli were entirely normal, some were lined by plump cells, and others contained macrophages. In a few there was a dense eosinophilic exudate which occasionally showed early organization. Scattered throughout the lung there was a mild to moderate inflammatory cell infiltration consisting of lymphocytes, plasma cells, and other mononuclear cells, some of which were pyroninophilic. Polymorphonuclear leucocytes were rare. This inflammatory response occurred as small collections of cells in the walls of alveoli, in the connective tissue septa, in the submucosa of small airways, and in the adventitia of large vessels. Infrequently a larger cellular accumulation was found. There was no overall increase of connective tissue nor any changes of the intrapulmonary blood vessels. Cells containing cytomegalovirus were frequent. Aspirated blood was readily evident.

Electron Microscopy.-The donor lung showed that the alveolar structure was intact and that there was a predominance of tall type II pneumonocytes. Minor non-specific cytological changes were evident in both epithelial and endothelial elements. The presence of occasional cells of the lympho-plasma series and the other light microscopical observations were confirmed. Interstitial fibroblasts seemed to be increased.

\section{Discussion}

The immediate cause of death was massive haemorrhage resulting from the perforation of the pulmonary artery by the necrotizing ulceration of the extrapulmonary part of the donor bronchus. This latter lesion was probably based on ischaemia to the donor bronchial stump together with superimposed bacterial infection. A rejection process does not seem to have been involved in the development of this, the fatal complication. The length of donor bronchus used may be critical in human transplantation, as it has been shown to be in canine studies (Huggins, 1959).

Assessment of the pulmonary changes is more difficult. There was little evidence of acute infection at the time of death although the organizing alveolar exudates may reflect an earlier infective episode. The widespread mononuclear inflammatory infiltrate might indicate cell-mediated rejection but such rejection would seem to be of relatively minor significance as its amount was minimal and there was little to suggest tissue damage. Indeed, it may have represented a response to previous bacterial or viral infection, the recrudescence of fibrosing alveolitis in the donor lung, or even some other non-specific activity. Although alveolar eosinophilic exudation has been considered as an unspecific mode of rejection (Veith and Blumenstock, 1971), it, too, may be a response to previous infection or, again, another non-specific phenomenon. Whatever its interpretation here, it does not seem to be a serious lesion.
Overall, it seems that although there may be an element of rejection this has not resulted in any significant lung damage and certainly did not cause the death of the patient.

Infection can be expected to be present in all cadaver lungs used in transplantation (Blumenstock, 1967), and pulmonary sepsis has been one of the major causes of death (Wildevuur and Benfield, 1970) and a serious contraindication to lung transplantation (Hardy et al., 1970). However, the presence of infection does not necessarily preclude long-term survival (Derom et al., 1971). Here, clinical chest infection was limited to six days, as indicated by the absence of adventitial sounds and purulent phlegm production. But a diagnosis of pulmonary sepsis could never be excluded because of the continual isolation of Pseudomonas aeruginosa from the sputum, as well as nonspecific radiological changes. These organisms were probably coming from the infected bronchial ulcer.

The clinical and radiological features that are associated with pulmonary sepsis may be indistinguishable from those of rejection (Wildevuur and Benfield, 1970). Recently a method has been described which assesses the activity of peripheral blood lymphocytes, using antilymphocyte globulin to inhibit the spontaneous formation of rosettes with sheep red blood cells (Bach and Antoined, 1968; Brain and Gordon, 1970; Salerni et al., 1970; Brain and Dormont, 1971). Munro et al. (1971) modified these techniques to give a rapid indication of lymphocyte suppression in the management of human renal allografts. Unpublished information suggests that the rosette inhibition test is not altered in the presence of bacterial, fungal, or viral infection unless there is evidence of bone marrow depression from sepsis (M. Bewick, personal communication, 1971). The central cell of the rosette may be a thymic-dependent lymphocyte (Reyes and Bach, 1970). Also, the less adherent thymic-dependent lymphocytes tend to concentrate in the elute rather than adhere to the cotton-wool columns during cellular separation (Greaves and Hogg, 1970). If this is so then the rosette inhibition test is a direct measurement of the activity of cells involved in cellmediated rejection.

The relation between circulating antibodies with subendothelial deposits of IgM and complement in renal allografts was described by Porter et al. (1968) although the specificity of the antibody was not clear (Mowbray, 1970). Such a relation has also been found in nephrotoxic serum nephritis (Feldman et al., 1963) and experimental allergic glomerulonephritis (Steblay, 1962). Circulating heart-binding antibody has been demonstrated by Ellis et al. (1970a) and Goldman (1970) on sarcolemmal membrane, but rarely on endothelial elements (Ellis et al., $1970 \mathrm{~b})$. This was associated with clinical rejection episodes in patients receiving heart allografts. Thus the detection of circulating organ-reactive antibody after transplantation is likely to be associated with humoral-antibody mechanisms associated with rejection.

The four episodes of incipient rejection seen here were each associated with clinical deterioration and a change in the rosette inhibition test, and on each occasion improvement in both followed an increase in immunosuppressive therapy. In two or three of these episodes in which it was measured lung-binding antibody was also present. Yet it was not possible in any of these four episodes to tell either clinically or radiologically whether the patient's illness was due to infection or rejection. The ability to detect changes in the immunological status of this patient was a major factor in his survival, as shown by the minimal histological evidence of rejection and pulmonary sepsis.

The physicians and surgeons involved are indebted to the many medical and administrative colleagues, nursing, physiotherapy, radiological, and technical staff throughout the hospital who contributed to the care of this patient.

\section{References}

Bach, J.-F., and Antoined, B. (1968). Nature, 217, 658. Bach, J.-F., and Dormont, J. (1971). Transplantation, 11, 96. 
Brain, P., and Gordon (1970). South African Medical fournal, 44, 684.

Blumenstock, D. A. (1967). Transplantation, 5, 917.

Derom, F., et al. (1971). Fournal of Thoracic and Cardiovascular Surgery, 61,

Ellis, R. J., Lillehei, C. W., and Zabriskie, J. B. (1970a). Fournal of the American Medical Association, 211, 1505.

Ellis, R. J., Lillehei, C. W., and Zabriskie, J. B. (1970b). Annals of Thoracic Surgery, 10, 432 .

Feldman, J. D., Hammer, D., and Dixon, F. (1963). Laboratory Investigation, 12,748

Goldman, B. S. (1970). Annals of Thoracic Surgery, 10, 441

Greaves, M. F., and Hogg, N. M. (1970). Proceedings of the Third Sigrid fulius Symposium on Cell Cooperation in the Immune Response. New York.

Hardy, J. D., et al. (1970). Fournal of Thoracic and Cardiovascular Surgery,

Huggins, C. E. (1959), Lancet, 2, 1059.
Hugh-Jones, P., et al. (1971). British Medical fournal, 3, 391.

Mowbray, J. F. (1970). Practitioner, 205, 282.

Munro, A., et al. (1971). British Medical fournal, 3, 271.

Organ Transplant Registry (1971). American College of Surgeons/National Institute of Health, Chicago.

Porter, K. A., et al. (1968). Laboratory Investigation, 18, 159.

Reyes, F., and Bach, J.-.F. (1970). Comptes Rendus Hebdomadaires des Ses, F., and Bach, J.-.F. (1970). Comptes Ren

Salerni, B., et al. (1970). In Proceedings of 5th Congress of European Society for Experimental Surgery, p. 108

Steblay, R. W. (1962). Fournal of Experimental Medicine, 116, 253.

Veith, F. J., and Blumenstock, D. A. (1971). Fournal of Surgical Research, 11, 33.

Wildevuur, C. R. H., and Benfield, J. R. (1970). Annals of Thoracic Surgery, $9,489$.

Williams, R. E. O., Blowers, R., Garrod, L. P., and Shooter, R. A. (1966). Hospital Infection. London, Lloyd Luke.

\title{
Smoking in Pregnancy and Vitamin $B_{12}$ Metabolism
}

\author{
JOHN M. MCGARRY， JOAN ANDREWS
}

British Medical fournal, 1972, 2, 74-77

\section{Summary}

In pregnancy the level of serum vitamin $B_{12}$ is lower in women who smoke than in non-smokers. This finding occurs independently of social class, parity, or level of haemoglobin. In addition, the mean serum $B_{12}$ level tends to be less in women who are anaemic and is less in those women who have smaller babies. These findings may be an effect of the cyanide content of tobacco smoke, since cyanide may be detoxified by a mechanism which depletes the stores of vitamin $B_{12}$ in the body.

\section{Introduction}

Two factors of importance in obstetrics which seem to be directly related to tobacco smoking are the increased incidence of small babies (Lowe, 1959; Herriot, Billewicz, and Hytten, 1962; O'Lane, 1963) and the decreased incidence of toxaemia and hypertension (Duffus and MacGillivray, 1968). Various ways have been suggested by which these effects may be produced, but little attention has been paid to the cyanide content of tobacco. However, Wilson and Matthews (1966) showed an association between tobacco smoking, cyanide detoxication, and serum vitamin $B_{12}$ levels in both normal subjects and those with certain neurological disorders.

The present study was designed to investigate any relation between smoking in pregnancy and serum $B_{12}$.

\section{Patients and Methods}

All women attending an antenatal booking clinic at one Cardiff hospital had a serum $B_{12}$ estimation. Patients were included in the study regardless of the stage of pregnancy at which they first booked, but subsequently results were subdivided according to the period of gestation. Obstetric data and details of smoking habit were obtained from the Cardiff Births Survey records. Inquiry into the cigarette smoking habits of each patient was made retrospectively during the puerperium.

Department of Obstetrics and Gynaecology, Welsh National School of Medicine, Cardiff

JOHN M. MCGARRY, M.R.C.o.G., Lecturer

JOAN ANDREWS, F.R.C.S., M.R.C.o.G., Lecturer (At present, Senior

Lecturer, Department of Obstetrics and Gynaecology, University of Liverpool)
The method used in estimating the serum $B_{12}$ was that utilizing Euglena gracilis (Hutner, Bach, and Ross, 1956). In all, 847 women were examined at the time of their first clinic visit. After exclusion of those pregnancies ending in multiple births or stillbirths, the results for the remaining 826 were recorded (Fig. 1).

Included were 22 patients of non-Caucasian extraction. As religious habits are particularly likely to influence serum $B_{12}$ levels these patients were studied separately. Only 4 of the 22 had a serum $B_{12}$ below $100 \mathrm{pg} / \mathrm{ml}$ (two Hindus, one Moslem, and one Sikh), and the mean level of the group was $146.7 \mathrm{pg} / \mathrm{ml}$, compared with $172 \cdot 2 \mathrm{pg} / \mathrm{ml}$ for the Caucasian population. These patients were then included in the general analysis as they form an increasingly large part of the population of this country.

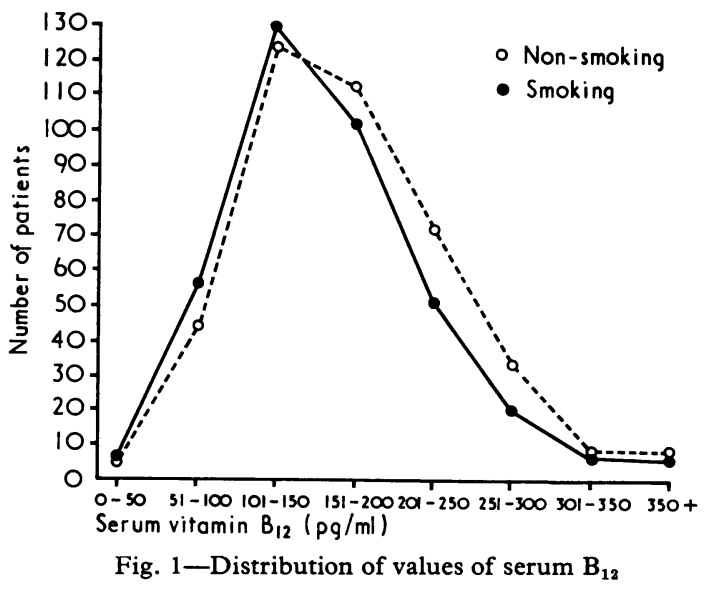

\section{Results}

Gestation Period.-Regardless of the period of gestation the mean level of serum $B_{12}$ among smokers is significantly less than among non-smokers (Table I). The difference is greatest in early pregnancy. Table II shows the fall in mean serum $\mathbf{B}_{12}$ associated with increasing smoking. The 29 "ex-smokers" included in this table are those who stopped smoking in early pregnancy and are omitted from all other tables.

Parity.-No significant variation in serum $B_{12}$ was found among women of different parity, although the $B_{12}$ level tends to be lower among those who smoke regardless of their parity (Table III). The difference is least among women of high parity who, regardless of their smoking habit, may already have low $\mathrm{B}_{12}$ stores. 